\title{
HMGB1 knockdown increases the radiosensitivity of esophageal squamous cell carcinoma by regulating the expression of molecules involved in DNA repair
}

\author{
GUOHU HAN ${ }^{1}$, RUI LING ${ }^{2}$, CHANGCHUN SUN ${ }^{1}$, XUEFENG WANG ${ }^{3}$, \\ YUEPENG ZHOU ${ }^{4}$, LIJIANG YU $^{1 *}$ and SHENZHA LIU ${ }^{1 *}$ \\ ${ }^{1}$ Department of Oncology, Jingjiang People's Hospital, The Seventh Affiliated Hospital of Yangzhou University, \\ Jingjiang, Jiangsu 214500; Departments of ${ }^{2}$ Oncology, ${ }^{3}$ Central Laboratory and ${ }^{4}$ Nuclear Medicine, \\ Affiliated Hospital of Jiangsu University, Zhenjiang, Jiangsu 212001, P.R. China
}

Received September 2, 2020; Accepted March 26, 2021

DOI: 10.3892/ol.2021.12764

\begin{abstract}
Radiotherapy is an effective therapeutic strategy in esophageal squamous cell carcinoma (ESCC). However, acquired radioresistance of cancer cells leads to radiotherapy failure. The present study aimed to investigate the mechanisms of the effect of high mobility group box 1 (HMGB1) on the radiation sensitivity of ESCC. Small interfering RNA (si) transfection was used to generate three groups of TE-1 cells (TE-1, negative control and TE-1+siHMGB1), and the protein expression levels of HMGB1 in TE-1 cells were detected by western blotting. These groups of TE-1 cells were irradiated with different doses $(0,2,4,6$ and $8 \mathrm{~Gy})$ of X-rays after transfection. Subsequently, the viability of TE-1 cells was detected using an MTT assay, and the survival fraction of TE-1 cells was observed using a colony formation assay. The apoptotic rate, reactive oxygen species (ROS) content and levels of phosphorylated (p)-histone $\mathrm{H} 2 \mathrm{AX}$ at $\mathrm{S} 139$ (p- $\gamma \mathrm{H} 2 \mathrm{AX}$ ) of the cells were detected by flow cytometry. The alterations in mRNA expression levels of nicotinamide adenine nucleotide phosphate oxidase (NOX)1 and NOX5 were detected by reverse transcription-quantitative $\mathrm{PCR}$, while the changes in protein levels of caspase-3, poly(ADP-ribose) polymerase, p-p38, p-ERK1/2 and p-JNK were detected by western blotting. The results revealed that HMGB1 knockdown significantly decreased cell viability, and the apoptosis rate of TE-1 cells transfected with siHMGB1 combined with radiation treatment was increased compared with that in cells with either
\end{abstract}

Correspondence to: Dr Lijiang Yu or Dr Shenzha Liu, Department of Oncology, Jingjiang People's Hospital, The Seventh Affiliated Hospital of Yangzhou University, 28 Zhongzhou Road, Jingjiang, Jiangsu 214500, P.R. China

E-mail: zgwy2020@aliyun.com

E-mail: 26310611@qq.com

Key words: high mobility group box 1 , histone $\mathrm{H} 2 \mathrm{AX}$, reactive oxygen species, radiosensitivity, esophageal carcinoma
siHMGB1 transfection or radiation treatment alone. HMGB1 knockdown increased nicotinamide adenine nucleotide phosphate oxidase-mediated ROS production and induced DNA damage via the MAPK signaling pathway, which may promote apoptosis and radiosensitivity after radiation in TE-1 cells. In conclusion, targeting HMGB1 may represent a promising strategy to increase the efficacy of radiation therapy for ESCC.

\section{Introduction}

Esophageal cancer is an invasive and lethal primary malignant type of cancer and had a worldwide 10\% 5-year survival rate in 2014 (1). Esophageal cancer has two major histopathologic types: Esophageal squamous cell carcinoma (ESCC) and esophageal adenocarcinoma (2). ESCC was the major esophageal cancer in Asia, Africa and South America in 2014 (3). Notably, China alone accounts for $\sim 50 \%$ of new cases worldwide and had multiple areas with incidence rates of $>100$ cases per 100,000 individuals in 2013 (4). Although great improvements have been made in the treatment of ESCC, including surgery, radiotherapy and chemotherapy, the number of patients who experience recurrence remains high (5). One of the main reasons for recurrence in numerous patients with ESCC is high radioresistance resulting from the disorders of multiple molecular and signaling pathways, such as ROS, DNA repair and apoptosis (6). Cancer treatment failure, particularly radioresistance to the DNA double strand breaks (DNA-DSBs) repair system, enhancement of the reactive oxygen species (ROS) scavenging rate, existence of a hypoxic zone and other disordered molecular expression have been identified in the tumor microenvironment after radiation $(7,8)$. Therefore, developing novel radiation sensitizing methods can facilitate overcoming radioresistance, thus improving the curative effect of radiotherapy clinically.

Excess ROS integrate with DNA and other molecules following radiation inside the cells, resulting in genetic defects, chromatin remodeling and other damages (9). A certain physiological level of ROS is required for maintaining cell proliferation and signal transduction; however, ROS accumulation can damage DNA, RNA and proteins, which leads 
to increased mutations and altered functions of numerous enzymes and proteins, as well as activation of oncogene products and inhibition of cancer suppressor proteins (9). Therefore, radiation induces ROS accumulation and DNA fragmentation, and elicits cancer cell apoptosis, which is important in mediating cell death in radiation therapy (10). Upon DNA damage in cells, histone $\mathrm{H} 2 \mathrm{AX}$ is phosphorylated on serine 139 to generate $\gamma-\mathrm{H} 2 \mathrm{AX}$, which is a marker for the cellular response to DNA-DSBs (11). Therefore, $\gamma$-H2AX expression after ionizing radiation reflects the formation of double stranded DNA breaks and DNA repair capacity. The MAPK signaling pathway is a key signaling pathway of malignant biological behaviors in multiple cancer types, which can stimulate cell proliferation, inhibition of apoptosis, and resistance to specific chemotherapeutics and ionizing radiation via DNA damage and accumulation of ROS (12-14). Furthermore, the MAPK pathway is a signal transduction pathway that is sensitive to oxidative stress in the majority of cell types, which could enhance radiation-induced cell proliferation inhibition by inactivation of ERK and trigger DNA damage by ROS overproduction $(15,16)$. However, improving the radiation sensitivity of ESCC remains a great challenge.

High mobility group box 1 (HMGB1) is a highly conserved DNA-binding protein, which is involved in gene transcription, chromatin remodeling, and DNA recombination and repair, as well as stabilizing nucleosome construction (17). Previous studies have demonstrated that HMGB1 expression is ubiquitously upregulated during the development and progression of various cancer types, including ESCC, neuroglioma and breast cancer (18-20). Endogenous HMGB1, which is involved in the proliferation of cancer cells and promotes cell invasion, is expressed in both the nucleus and the cytoplasm (21). In ESCC, downregulated HMGB1 inhibits vascular endothelial growth factor-C expression and the proliferation of cancer cells through the receptor for advanced glycation end-products (RAGE) signaling pathway, thus functioning as a tumor promoter (22). Furthermore, the non-histone chromosomal protein HMGB1 serves an important role in enhancing ligation reactions of DNA-DSBs (23), and downregulation of HMGB1 modulates telomere homeostasis and sensitizes breast cells to radiotherapy (24). Furthermore, Zhang et al (25) reported that the increase in HMGB1 expression may be associated with radioresistance in esophageal carcinoma cells. The present study explored the regulatory role of HMGB1 in radiosensitivity of ESCC cells to provide a novel target for anticancer strategies.

\section{Materials and methods}

Cell culture and irradiation. The human TE-1 ESCC cell line was obtained from the Shanghai GeneChem Co., Ltd. and was cultured in DMEM (Gibco; Thermo Fisher Scientific, Inc.) supplemented with $10 \%$ fetal bovine serum (FBS; Biological Industries) and $100 \mathrm{U} / 1$ penicillin sodium/100 U/1 streptomycin sulfate (Invitrogen; Thermo Fisher Scientific, Inc.). The cells were incubated in a $95 \%$ air $/ 5 \% \mathrm{CO} 2$ humidified incubator at $37^{\circ} \mathrm{C}$ for 24,48 and $72 \mathrm{~h}$. Cells were exposed to $6 \mathrm{MV}-\mathrm{X}$-rays radiation with a linear accelerator source (Varian Medical Systems) at a cumulative dose of 0-8 Gy at a fixed dose rate of $200 \mathrm{cGy} / \mathrm{min}$ at room temperature. The $0 \mathrm{~Gy}$ group was used as the control group.
MTT assay. An MTT assay was used to assess cell viability. Cells in the logarithmic growth phase were plated at a density of $4 \times 10^{3}$ cells per well into 96 -well plates in complete medium and cultured overnight at $37^{\circ} \mathrm{C}$. The cells were then subjected to various treatments (siHMGB1, radiation or both) for 24,48 and $72 \mathrm{~h}$ at $37^{\circ} \mathrm{C}$. The remaining medium was discarded from the wells, $20 \mu \mathrm{l}$ MTT and $100 \mu \mathrm{l}$ medium were added to each well, and cells were incubated at $37{ }^{\circ} \mathrm{C}$ for an additional $4 \mathrm{~h}$. Subsequently, the supernatant was discarded, and the reaction was stopped with $150 \mu \mathrm{l}$ dimethyl sulfoxide for $10 \mathrm{~min}$ to dissolve MTT. Finally, the absorbance value was quantified at a wavelength of $490 \mathrm{~nm}$ on a microplate reader, and each experiment was repeated independently at least three times. Cell viability was calculated using the following formula: Mean optical density of treated cells/mean optical density of control cells.

siRNA sequences and transfection. HMGB1 and RAGE gene expression specific siRNA fragments and one scrambled shRNA (negative control) were designed and synthesized by Shanghai GenePharma Co., Ltd., according to the manufacturer's protocols. The sequences of the siRNAs were as follows: si-HMGB1 forward, 5'-GCUCAAGGAGAAUUUGUAATT-3' and reverse, 5'-UUACAAAUUCUCCUUGAGCTT-3'; si-RAGE forward, 5'-GCCGGAAAUUGUGAAUCCUTT-3' and reverse, 5'-AGGAUUCACAAUUUCCGCCTT-3'; and scrambled shRNA forward, 5'-UUCUCCGAACGUGUCACGUTT-3' and reverse, 5'-ACGUGACACGUUCGGAGAATT-3'. A total of TE-1 cells $\left(4 \times 10^{5}\right)$ were seeded into 6-well plates for $16 \mathrm{~h}$ and then transfected with 100 pmol siRNA in serum-free medium for $8 \mathrm{~h}$ at $37^{\circ} \mathrm{C}$. Negative control siRNA $(20 \mu \mathrm{M})$ and siHMGB1/siRAGE $(20 \mu \mathrm{M})$ were transfected into cells using Lipofectamine $^{\circledR} 2000$ (Invitrogen; Thermo Fisher Scientific, Inc.). After that, the medium was replaced with serum-supplemented medium for $24 \mathrm{~h}$ at $37^{\circ} \mathrm{C}$. The time interval between transfection and subsequent experimentation was $48 \mathrm{~h}$. Negative controls using non-transfected cells and empty-vector were performed in parallel and then cells were harvested for analysis of protein expression.

Clonogenic survival assay. A total of $1 \times 10^{3}$ cells were seeded into 6-well plates in triplicate overnight. The transfection subsection of cells was performed as previously described. After radiation $(0,2,4,6$ or $8 \mathrm{~Gy})$, the cells were incubated for 8 days with $5 \% \mathrm{CO}_{2}$ at $37{ }^{\circ} \mathrm{C}$ to allow the formation of colonies. Subsequently, colonies were washed with PBS, and subsequently fixed for $20 \mathrm{~min}$ with $70 \%$ ethanol at room temperature and stained for 20 min with $0.5 \%$ crystal violet (Sigma-Aldrich; Merck KGaA) at room temperature. Colonies containing $>50$ cells were counted under a light microscope (x200 magnification; Olympus Corporation). The surviving fraction was calculated as the ratio of the plating efficiency of the treated cells to that of control cells. The sensitization enhancement ratio (SER) was calculated as the mean inactivation dose in the control group divided by that in the treated group.

Detection of cell apoptosis by flow cytometry. Apoptosis was detected using an Annexin V-phycoerythrin and 7-amino-actinomycin D (Annexin V-PE/7-AAD) apoptosis kit (Hangzhou Multi Sciences (Lianke) Biotech Co., Ltd.). Cells $\left(4 \times 10^{5}\right)$ were 
plated overnight in 6-well plates, transfected with or without siHMGB1 for $24 \mathrm{~h}$, and then cultured for $24 \mathrm{~h}$ after radiation (4 Gy). A total of $1 \times 10^{6}$ cells $/ \mathrm{ml}$ of treated cells in each group were collected and double-stained using Annexin V-PE/7-AAD for $15 \mathrm{~min}$ at $25^{\circ} \mathrm{C}$. Next, cell apoptosis was quantified by flow cytometry (FACSCalibur; BD Biosciences) within $1 \mathrm{~h}$, and the results were analyzed using the FlowJo software (version 7.6.1; Tree Star, Inc.).

$R N A$ extraction and reverse transcription-quantitative $P C R$ (RT-qPCR). Total RNA from each group of cultured TE-1 cells was isolated using TRIzol ${ }^{\circledR}$ reagent (Invitrogen; Thermo Fisher Scientific, Inc.). RNA was dissolved with RNase-free water and stored at $-80^{\circ} \mathrm{C}$. RNA concentrations were detected by NanoDrop spectrophotometry (Thermo Fisher Scientific, Inc.). cDNA synthesis and its reaction condition were performed with a Prime-Script ${ }^{\text {TM }}$ RT Reagent kit (Takara Biotechnology Co., Ltd.), according to the manufacturer's protocol. RT-qPCR was carried out using a Stratagene Mx3000Pтм Real-Time PCR System (Agilent Technologies, Inc.) and SYBR Premix Ex Taq ${ }^{\mathrm{TM}}$ (Takara Biotechnology Co., Ltd.) with the following primers (Generay Biotech Co., Ltd.): NADPH oxidase (NOX)1 forward, 5'-CAAGGCCACTGACATCGT-3' and reverse, 5'-CAGATTACCGTCCTTATTCCTA-3'; NOX5 forward, 5'-GATGACCCACCCAATAAGAC-3' and reverse, 5'-GCCTCTGGTTCCCTCACTT-3'; and GAPDH forward, 5'-TCAACGGATTTGGTCGTATTG-3' and reverse, 5'-TGGGTGGAATCATATTGGAAC-3'. GAPDH was used as the internal control. The following thermocycling conditions were used for amplification: Initial denaturation at $95^{\circ} \mathrm{C}$ for $2 \mathrm{~min}$, followed by 40 cycles of denaturation at $95^{\circ} \mathrm{C}$ for $15 \mathrm{sec}$, annealing at $60^{\circ} \mathrm{C}$ for $20 \mathrm{sec}$ and extension at $72^{\circ} \mathrm{C}$ for $15 \mathrm{sec}$. Data analysis was performed using the comparative $\mathrm{Cq}$ method as previously described (19).

Detection of intracellular ROS by flow cytometry. Intracellular ROS levels were detected in living cells using the 2',7'-dichlorodihydrofluorescein diacetate (DCFH-DA) probe (Beyotime Institute of Biotechnology), which is converted by ROS into the fluorescent product 2',7'-dichlorofluorescein (10). A total of $2 \times 10^{6}$ cells at $37^{\circ} \mathrm{C}$ were transfected with or without siHMGB1 for $24 \mathrm{~h}$ and subsequently irradiated with 4-Gy irradiation for $12 \mathrm{~h}$. Subsequently, the cells were isolated and incubated with $10 \mu \mathrm{M}$ DCFH-DA diluted in serum-free medium for $25 \mathrm{~min}$ at $37^{\circ} \mathrm{C}$ in a dark humidified incubator, which was added directly to the cell culture media to a final concentration of $10 \mu \mathrm{g} / \mathrm{ml}$. After treatment, the cells were washed three times with PBS at room temperature for a total of 5 min and suspended in serum-free medium. Subsequently, the ROS levels were measured immediately via flow cytometry (FACSCalibur; BD Biosciences) with an excitation wavelength of $488 \mathrm{~nm}$ and an emission wavelength of $525 \mathrm{~nm}$. Serum-free medium was used as a negative control. Fluorescence data were analyzed using the FlowJo software (version 7.6.1; Tree Star, Inc.).

Analysis of DNA-DSBs using flow cytometry. Cells at $37^{\circ} \mathrm{C}$ were transfected with siHMGB1 for $24 \mathrm{~h}$ prior to irradiation with 4 Gy X-rays for $1 \mathrm{~h}$. Cells were harvested with trypsin and washed with ice-cold PBS twice. Subsequently, the cells were fixed in $4 \%$ paraformaldehyde for $30 \mathrm{~min}$ at room temperature, and then permeabilized with Tris-buffered saline containing $0.25 \%$ Triton X-100 on ice for $15 \mathrm{~min}$, followed by final resuspension containing 5\% BSA (Sigma-Aldrich; Merck $\mathrm{KGaA}$ ) in PBS for $1 \mathrm{~h}$ at $25^{\circ} \mathrm{C}$. Next, the cells were incubated with an anti-phospho-histone H2AX (Ser139) monoclonal antibody (dilution, 1:400 in PBS; cat. no. 9718; Cell Signaling Technology, Inc.) as the primary antibody overnight at $4^{\circ} \mathrm{C}$. The cells were then washed with PBS three times at room temperature and incubated with secondary antibody Cy3-conjugated goat anti-rabbit IgG (1:200; cat. no. GB21303; Wuhan Servicebio Technology Co., Ltd.) for $1 \mathrm{~h}$ at $25^{\circ} \mathrm{C}$ and then washed with PBS twice. Phospho- $\gamma \mathrm{H} 2 \mathrm{AX}$ (p- $\gamma \mathrm{H} 2 \mathrm{AX}$ ) levels were measured by flow cytometry (FACSCalibur; BD Biosciences). Untreated cells were used as the negative control. Data were analyzed using the FlowJo software (version 7.6.1; Tree Star, Inc.).

Assessment of protein expression by western blot analysis. Cells were treated as aforementioned with ionizing radiation, siRNA or a combination of the two treatments, which were divided into the following groups: TE-1, negative control, 4-Gy, siHMGB1, siRAGE, 4-Gy+siHMGB1, 4-Gy+siRAGE. Cells were collected and washed twice with PBS. The cellular protein was extracted using RIPA lysis buffer (Beijing Solarbio Science \& Technology Co., Ltd.) at $4^{\circ} \mathrm{C}$, according to the manufacturer's protocol, and total cellular protein concentrations were determined with a BioMate 3S (Thermo Fisher Scientific, Inc.) according to the manufacturer's protocols. Subsequently, $5 \mu \mathrm{g}$ protein/lane for each sample was separated by electrophoresis on a 10-15\% SDS-polyacrylamide gel, and then electronically transferred onto a polyvinylidene fluoride membrane (EMD Millipore). After blocking for $1 \mathrm{~h}$ at $37^{\circ} \mathrm{C}$ with Tris-buffered saline containing 1\% Tween-20 (TBST) or $5 \%$ BSA, the membranes were incubated with the primary antibody at $4^{\circ} \mathrm{C}$ overnight. The following primary antibodies were diluted in PBS at 1:500 and purchased from Cell Signaling Technology, Inc.: ERK1/2 (cat. no. 9194S), p-ERK1/2 (cat. no. $4370 \mathrm{~T}$ ), JNK (cat. no. $9252 \mathrm{~S}$ ), p-JNK (cat. no. 9251S), p38 (cat.no.9212S), p-p38 (cat. no. 9216S), RAGE (cat. no. 42544S), HMGB1 (cat. no. 3935S), $\beta$-actin (cat. no. 12620S), caspase-3 (cat. no. 14220S) and cleaved-poly(ADP-ribose) polymerase (PARP; cat. no. 9185S). Subsequently, the membranes were washed three times with TBST and incubated for $1 \mathrm{~h}$ at $37^{\circ} \mathrm{C}$ with the anti-rabbit secondary antibody conjugated to horseradish peroxidase (dilution, 1:5,000 in TBST; cat. no. 7076; Cell Signaling Technology, Inc.). After washing three times with TBST, the bands were detected using Pierce ECL Plus Western Blotting substrate (Thermo Fisher Scientific, Inc.) and scanned using a FluorChem FC3 imaging system (ProteinSimple). The images were semi-quantified with AlphaView software (version 3.4.0; ProteinSimple), normalized to $\beta$-actin (standard control) and expressed as the fold change compared with the control

Statistical analysis. Data are presented as the mean \pm SEM and were derived from $\geq 3$ independent experiments. Unpaired Student's t-test was used to compare differences between two groups (Fig. 1B). Multiple group comparisons of the means were carried out by one-way ANOVA followed by Tukey's post hoc test. SPSS v20.0 (IBM Corp.) and GraphPad Prism 8.02 
(GraphPad Software, Inc.) were used to perform the analysis. $\mathrm{P}<0.05$ was considered to indicate a statistically significant difference.

\section{Results}

HMGB1 knockdown enhances radiosensitivity in TE-1 cells. A HMGB1 knockdown cell line was constructed to investigate the role of HMGB1 in the radiotherapy of ESCC, and the transfection efficiency was detected using western blot analysis (Fig. 1A). To investigate the effect of HMGB1 knockdown on ionizing radiation in TE-1 cells, an MTT assay was used to detect changes in viability after siHMGB1 transfection at 24 , 48 and $72 \mathrm{~h}$ in TE-1 cells. As shown in Fig. 1B, siHMGB1 treatment induced a significant decrease in cell viability compared with that of cells without transfection at all time points. TE-1 cell viability after 2-Gy radiation significantly decreased compared with the effects of the non-transfected cells, whereas irradiation at 4 and $8 \mathrm{~Gy}$ did not significantly reduce the number of cells compared with the effects of 2-Gy irradiation (Fig. 1C). siHMGB1 treatment significantly decreased cell viability compared with that of cells without transfection after different doses of radiation (2,4 and 8-Gy). Cell viability was decreased after exposure to radiation in a dose-dependent manner in HMGB1 knockdown cells (Fig. 1C). Furthermore, a clonogenic survival assay was performed to assess whether HMGB1 knockdown had potential radiosensitization activity. As shown in Fig. 1D and E, treatmen of TE-1 cells with siHMGB1 for $24 \mathrm{~h}$ prior to radiation led to a survival curve shift compared with that of untreated TE-1 cells, with a SER of 1.62. The present results demonstrated that the viability of TE-1 cells could not be inhibited by increasing the dose of ionizing radiation $(2,4$ and 8 -Gy), which was probably due to radioresistance. However, HMGB1 knockdown could increase the radiosensitivity of TE-1 cells to radiotherapeutic agents.

HMGB1 knockdown enhances radiation-induced apoptosis in TE-1 cells. The levels of apoptosis of TE-1 cells after radiation were examined using Annexin V-PE and 7-AAD staining to verify whether HMGB1 knockdown enhanced radiation-induced inhibition of cell viability through apoptosis. As shown in Fig. 2A and B, the apoptosis rate of TE-1 cells after exposure to 4-Gy radiation for $24 \mathrm{~h}$ was significantly increased compared with that of cells that were not irradiated. However, siHMGB1 treatment significantly increased cell apoptosis after radiation compared with that of cells without transfection. Consistent with these findings, a marked increase in the expression levels of the pro-apoptotic proteins caspase-3 and cleaved PARP was observed after combined treatment of radiation and transfection by western blotting (Fig. 2C). These results demonstrated that the radiosensitizing effect of HMGB1 knockdown may be caused by induction of apoptosis in TE-1 cells.

HMGB1 knockdown increases NOX-mediated ROS production in irradiated TE-1 cells. Radiation can induce accumulation of ROS production, leading to cell damage and apoptosis (26). In the present study, the levels of ROS production after radiation were detected to examine whether HMGB1 knockdown could promote radiation-induced ROS production. Compared with that of TE-1 control cells, ROS production was not significantly altered after irradiation at $4 \mathrm{~Gy}$, whereas siHMGB1 treatment significantly increased the levels of ROS production (Fig. 3A and B). However, HMGB1 knockdown combined with radiation resulted in higher ROS production than either siHMGB1 or radiation alone (Fig. 3A and B). These results demonstrated that the combination of HMGB1 knockdown and radiation caused the upregulation of ROS production, which may promote an increase in apoptosis of TE-1 cells after radiation.

The mRNA expression levels of NADPH oxidases were further detected to examine whether ROS production was induced by HMGB1 knockdown. It was revealed that the mRNA expression levels of NOX1 and NOX5 were significantly increased by HMGB1 knockdown or radiation treatment alone, while HMGB1 knockdown combined with radiation resulted in higher NOX1 and NOX5 mRNA expression compared with radiation alone (Fig. 3C). These results demonstrated that NADPH oxidase may be crucial in the radiation-induced generation of ROS following knockdown of HMGB1.

$X$-rays (4 Gy) enhance HMGB1 knockdown-induced DNA damage in TE-1 cells. ROS accumulation has been demonstrated to cause DNA damage and trigger radiation-induced cell apoptosis (27). The levels of $\mathrm{p}-\gamma \mathrm{H} 2 \mathrm{AX}$ after radiation were examined to investigate whether 4-Gy X-rays could promote HMGB1 knockdown-induced DNA damage. Compared with that of TE- 1 control cells, $\mathrm{p}-\gamma \mathrm{H} 2 \mathrm{AX}$ expression was significantly altered after 4-Gy radiation or siHMGB1 transfection (Fig. 4). However, HMGB1 knockdown combined with radiation resulted in higher $\mathrm{p}-\gamma \mathrm{H} 2 \mathrm{AX}$ production than either siHMGB1 or radiation alone (Fig. 4). These results demonstrated that the combination of HMGB1 knockdown and radiation was associated with increased DNA damage, which may promote the apoptosis of TE-1 cells after radiation.

MAPK signaling pathway is involved in the HMGB1-mediated promotion of radioresistance. The MAPK signaling pathway is an oxidative stress-sensitive signal transduction pathway that is involved in radiation-induced cell apoptosis (12-14). The present study evaluated whether the MAPK signaling pathway also mediated the effects of apoptosis of HMGB1 knockdown during radiation of TE-1 cells. It was revealed that the levels of p-p38/p-38 and p-ERK1/2/ERK1/2 decreased, while $\mathrm{p}-\mathrm{JNK} / \mathrm{JNK}$ increased by HMGB1 knockdown along with radiation compared with the effects produced by either siHMGB1 or radiation alone (Fig. 5A). To determine whether HMGB1 promoted MAPK signaling-mediated radioresistance via RAGE, which is an HMGB1 receptor, TE-1 cells were transfected with siRAGE (Fig. 5B) and treated with radiation alone or transfected with siRAGE and treated with radiation. As shown in Fig. 5C, RAGE knockdown combined with radiation increased p-JNK levels, and decreased p-p38 and $\mathrm{p}$-ERK1/2 levels. Therefore, these results indicated that the MAPK signaling pathway is involved in the process of HMGB1-promoting radioresistance via RAGE in TE-1 cells.

\section{Discussion}

HMGB1 expression is frequently upregulated in human tumors (18-20); however, to the best of our knowledge, its 
A

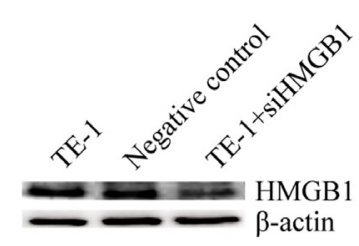

C

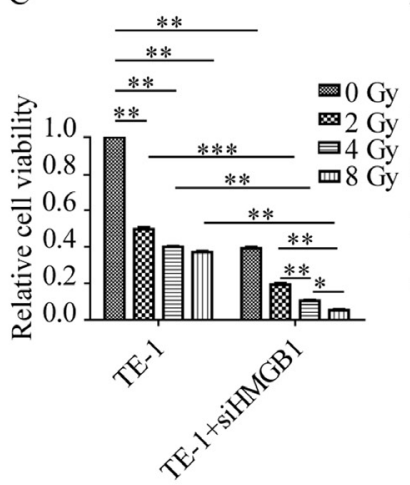

$\mathrm{D}$
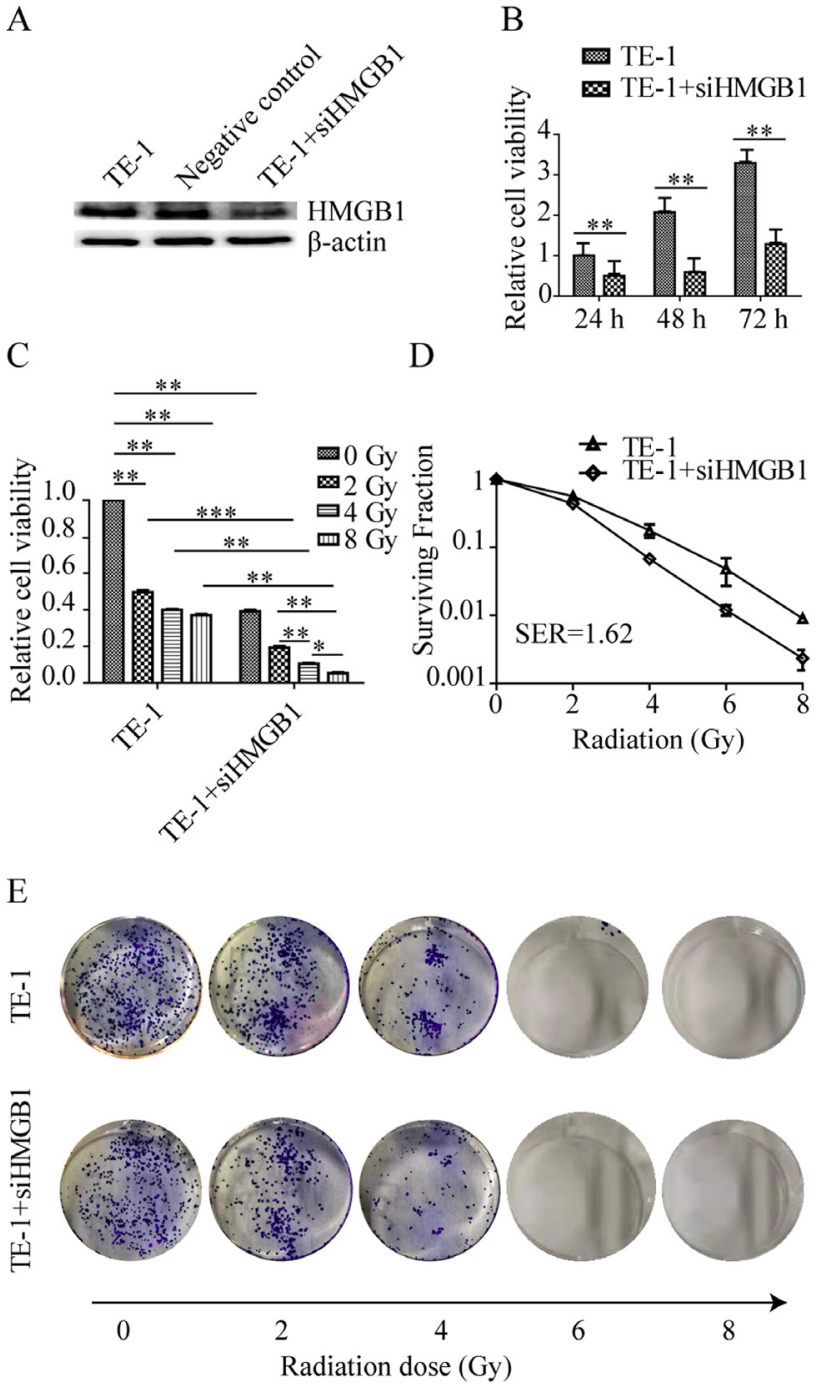

Figure 1. HMGB1 knockdown enhances radiosensitivity in TE-1 cells. (A) Western blot analysis of HMGB1 knockdown in TE-1 cells transfected with siHMGB1 for $48 \mathrm{~h}$. (B) An MTT assay was used to detect changes in cell viability after siHMGB1 transfection at 24, 48 and $72 \mathrm{~h}$ in TE-1 cells. Differences between two groups were compared by Unpaired Student's t-test (C) An MTT assay was used to detect changes in the viability of TE-1 cells transfected with siHMGB1 for $24 \mathrm{~h}$ prior to being subjected to different doses of ionizing radiation for $24 \mathrm{~h}$. (D) TE-1 cells were seeded in 6-well plates and treated with siHMGB1 for $24 \mathrm{~h}$. Irradiation was conducted at incremental doses of $\leq 8 \mathrm{~Gy}$. Colonies with $>50$ cells were counted after 8 days of culture. The SER was calculated as the mean inactivation dose in the control group divided by that in the treated group. (E) Images of 6-well plates in a representative experiment are shown. data are presented as the mean \pm SEM and were derived from $\geq 3$ independent experiments. ${ }^{*} \mathrm{P}<0.05,{ }^{* *} \mathrm{P}<0.01,{ }^{* * *} \mathrm{P}<0.001$. HMGB1, high mobility group box 1; SER, sensitization enhancement ratio; si, small interfering RNA.

relevance in cancer radiotherapy is unknown. HMGB1-deficient tumors have an impaired ability to recruit innate immune cells into chemotherapy-treated tumor tissues, indicating that HMGB1 serves an important role in antitumor immunity (28). In the majority of epithelial cancer types, including ESCC, HMGB1 knockdown can induce apoptosis (22). Activated caspase-3 and cleaved PARP are well-documented measurements of apoptosis $(29,30)$. The present study revealed that HMGB1 knockdown combined with radiation reduced cancer cell viability and increased apoptosis, indicating that HMGB1 knockdown-induced cell apoptosis is a major mechanism for HMGB1 knockdown-mediated radiosensitivity.
A

TE-1

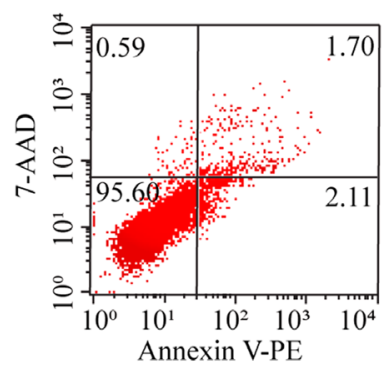

TE-1+siHMGB1
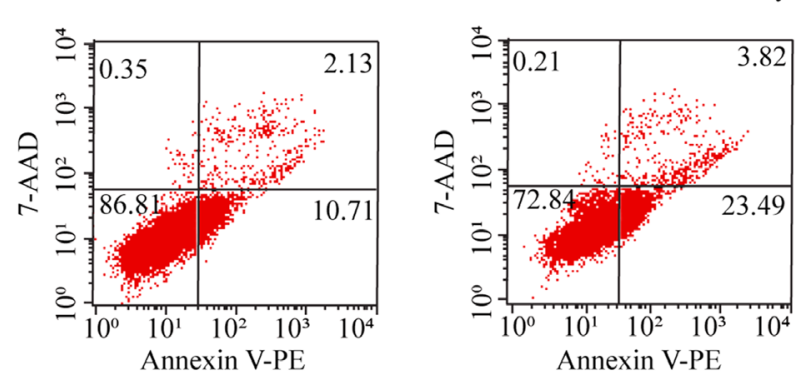

B

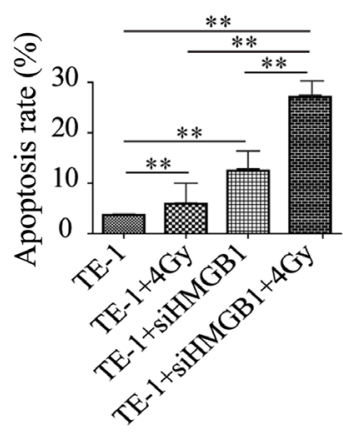

$\mathrm{C}$

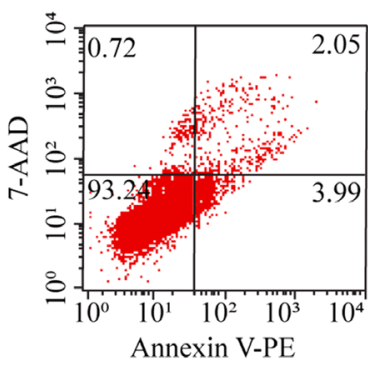

TE-1+siHMGB1+4Gy

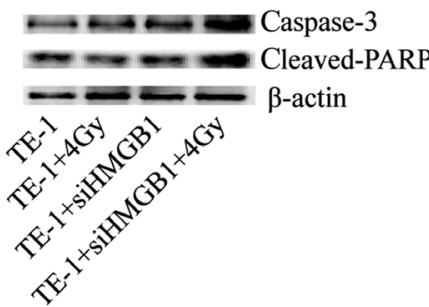

Figure 2. HMGB1 knockdown enhances radiation-induced apoptosis in TE-1 cells. (A) Apoptosis was analyzed using flow cytometry in TE-1 cells transfected with or without siHMGB1 for $24 \mathrm{~h}$ and then irradiated with 4-Gy irradiation for $24 \mathrm{~h}$ after staining with Annexin V-PE and 7-AAD. (B) Bar graph depicting the percentages of apoptosis of TE-1 cells transfected with siHMGB1, treated with irradiation or both. (C) TE-1 cells were treated as described in (A), and the expression levels of apoptosis-associated proteins were analyzed by western blotting. $\beta$-actin was used as a loading control. All data are presented as the mean \pm SEM and were derived from $\geq 3$ independent experiments. ${ }^{* *} \mathrm{P}<0.01$. 7-AAD, 7-amino-actinomycin D; HMGB1, high mobility group box 1; PARP, poly(ADP-ribose) polymerase; PE, phycoerythrin; si, small interfering RNA.

However, the exact mechanism by which HMGB1 knockdown increases radiation-induced apoptosis is unknown. ROS may be a risk factor in radiation-induced DNA damage (24). There are numerous types of ROS, including superoxide, hydrogen peroxide and highly toxic hydroxyl radicals (31). NOX is the main source of ROS, and is mainly composed of six subunits: NOX1, NOX3, NOX4, NOX5, dual oxidase (DUOX)1 and DUOX2 (32). Consistent with previously reported observations that HMGB1 knockdown combined with cordycepin treatment had anti-proliferative and pro-apoptotic effects via increasing the ROS levels in the K562 human chronic myeloid leukemia cell line (33), siHMGB1 treatment enhanced the mRNA expression levels of NOX1 and NOX5, and increased intracellular ROS levels in irradiated TE-1 cells in the present study. It has been reported that diabetes and intravitreal 
A
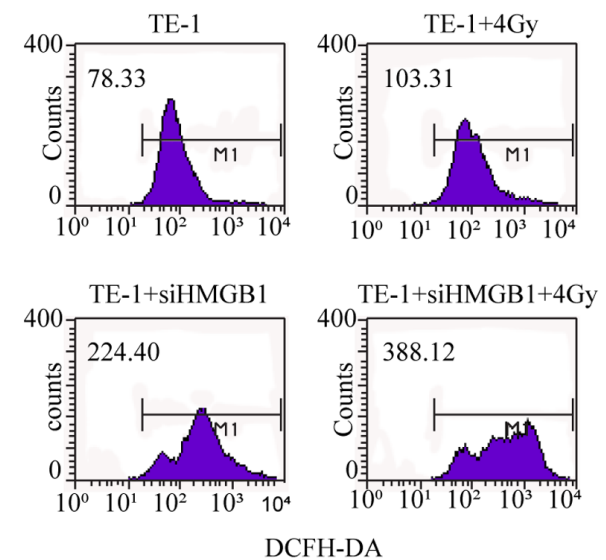

B

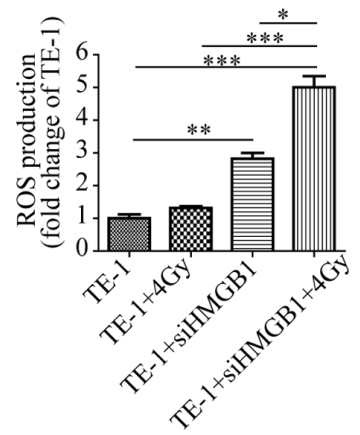

C

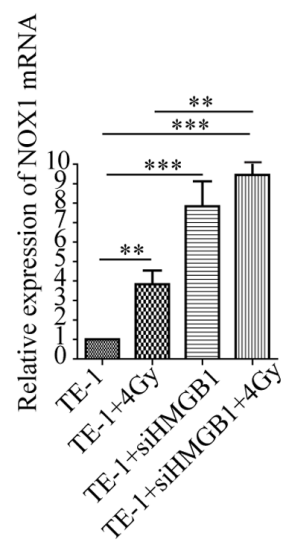

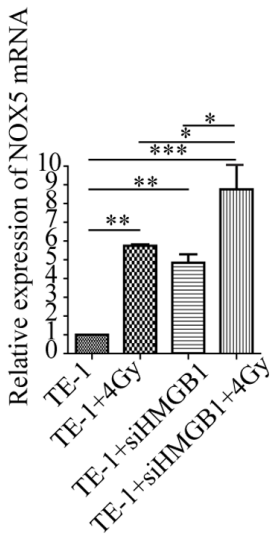

Figure 3. HMGB1 knockdown increases NOX-mediated ROS production in irradiated TE-1 cells. (A) ROS production was assessed via detection of 2',7'-dichlorofluorescein expression using flow cytometry in TE-1 cells transfected with or without siHMGB1 for $24 \mathrm{~h}$ and then irradiated with 4 -Gy irradiation for $12 \mathrm{~h}$. (B) Bar graph depicting the fold change in ROS production in TE-1 cells transfected with siHMGB1, treated with irradiation or both. All data are presented as the mean \pm SEM and were derived from $\geq 3$ independent experiments. (C) mRNA expression levels of NOX1 and NOX5 in cells transfected with siHMGB1, treated with irradiation or both are shown as relative levels compared with those of TE-1 control cells. Data are presented as the mean \pm SEM and were derived from $\geq 3$ independent experiments. ${ }^{*} \mathrm{P}<0.05,{ }^{* *} \mathrm{P}<0.01,{ }^{* * *} \mathrm{P}<0.001$. DCFH-DA, 2',7'-dichlorodihydrofluorescein diacetate; HMGB1, high mobility group box 1; NOX, NADPH oxidase; ROS, reactive oxygen species; si, small interfering RNA.
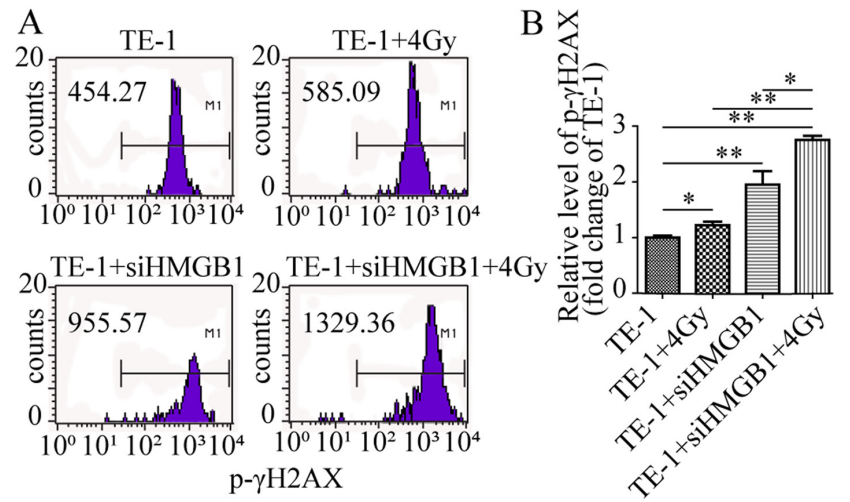

Figure 4. HMGB1 knockdown enhances X-rays-induced DNA damage in TE-1 cells. (A) DNA damage was assessed via detection of the levels of p- $\gamma \mathrm{H} 2 \mathrm{AX}$ using flow cytometry in TE-1 cells transfected with or without siHMGB1 for $24 \mathrm{~h}$ and then irradiated at $4 \mathrm{~Gy}$ for $1 \mathrm{~h}$. (B) Bar graph depicting the relative levels of $\mathrm{p}-\gamma \mathrm{H} 2 \mathrm{AX}$ in TE- 1 cells transfected with siHMGB1, treated with irradiation or both. Data are presented as the mean \pm SEM and were derived from $\geq 3$ independent experiments. ${ }^{*} \mathrm{P}<0.05,{ }^{* *} \mathrm{P}<0.01$. HMGB1, high mobility group box 1 ; si, small interfering RNA; $\mathrm{p}-\gamma \mathrm{H} 2 \mathrm{AX}$, phosphorylated histone $\mathrm{H} 2 \mathrm{AX}$ at $\mathrm{S} 139$.

injection of HMGB1 in normal rats induces upregulation of ROS and NOX2 in the retina (34), and that the rate of generation of ROS decreases upon exposure to HMGB1 inhibition in rat tubulo-epithelial cells (35). The role of HMGB1 in ROS production remains to be investigated in future studies. Therefore, it was concluded that HMGB1 knockdown promoted radiation-induced NOX1 and NOX5-derived ROS generation in ESCC. In addition, ROS accumulation was involved in the regulation of DNA damage, triggering apoptosis signal transduction pathways and resulting in the promotion of radiation sensitivity in TE-1 cells.

Ionizing radiation induces various types of damage in cellular DNA, which is considered to be the target of biological effects of radiation, by both direct energy deposition on DNA and reactions with diffusible water radicals (36). Radioresistance decreases the therapeutic effect of cervical cancer, and one of the main reasons for this is the influence of apoptosis and DSB repair (37). Increased $\mathrm{p}-\gamma \mathrm{H} 2 \mathrm{AX}$ is a sensitive and precise hallmark for chromatin-induced DNA-DSBs by ionizing radiation or oxidative damage (11). It was revealed that HMGB1 knockdown or its combination with radiation significantly increased the levels of $\mathrm{p}-\gamma \mathrm{H} 2 \mathrm{AX}$ compared with radiation treatment alone. Therefore, HMGB1 knockdown markedly increased DNA-DSBs in irradiated cells, and sensitized TE-1 cells to radiation-induced apoptosis by increasing DNA damage.

Endogenous HMGB1 binds to RAGE on the cell surface and to Toll-like receptor (TLR)2, TLR4 and TLR9 in the cytoplasm, which activates MAPK, thus promoting angiogenesis, unlimited replicative potential, tissue invasion and metastasis $(38,39)$. Elevated RAGE expression promotes cell viability in ESCC (22). RAGE knockdown increases cell apoptosis and diminishes cell survival by ROS-induced oxidative injury in pancreatic tumor cells (40). Furthermore, the MAPK signaling pathway is involved in the regulation of cell apoptosis $(15,16)$. Pro-survival ERK signaling is a critical effector downstream of epidermal growth factor receptor signaling, which enhances DNA-DSB repair in human glioma cells (16). JNK, a stress-activated protein kinase (41), can be activated by ionizing radiation or ROS $(41,42)$. Activation of JNK by radiation is associated with apoptotic cell death-mediated Bcl-2 downregulation (43). Furthermore, previous studies have demonstrated that pretreatment with JNK inhibitor can prevent the activation of caspase- 3 and cleavage PARP triggered by radiation $(29,30)$, indicating that ERK downregulation and JNK upregulation are the main mechanisms promoting cell death in cancer in response to radiation $(14,16)$. Consistent with a previous study (24), the present results demonstrated that HMGB1 or RAGE knockdown induces upregulation of p-JNK in TE-1 cells after radiation, whereas p-ERK levels decrease, suggesting that the MAPK signaling pathway is involved in regulating DNA damage and ROS generation, increasing apoptosis when HMGB1 knockdown is combined with radiation. 
A
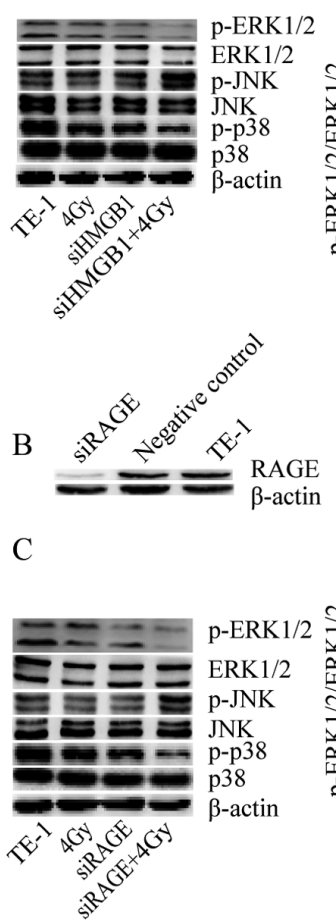
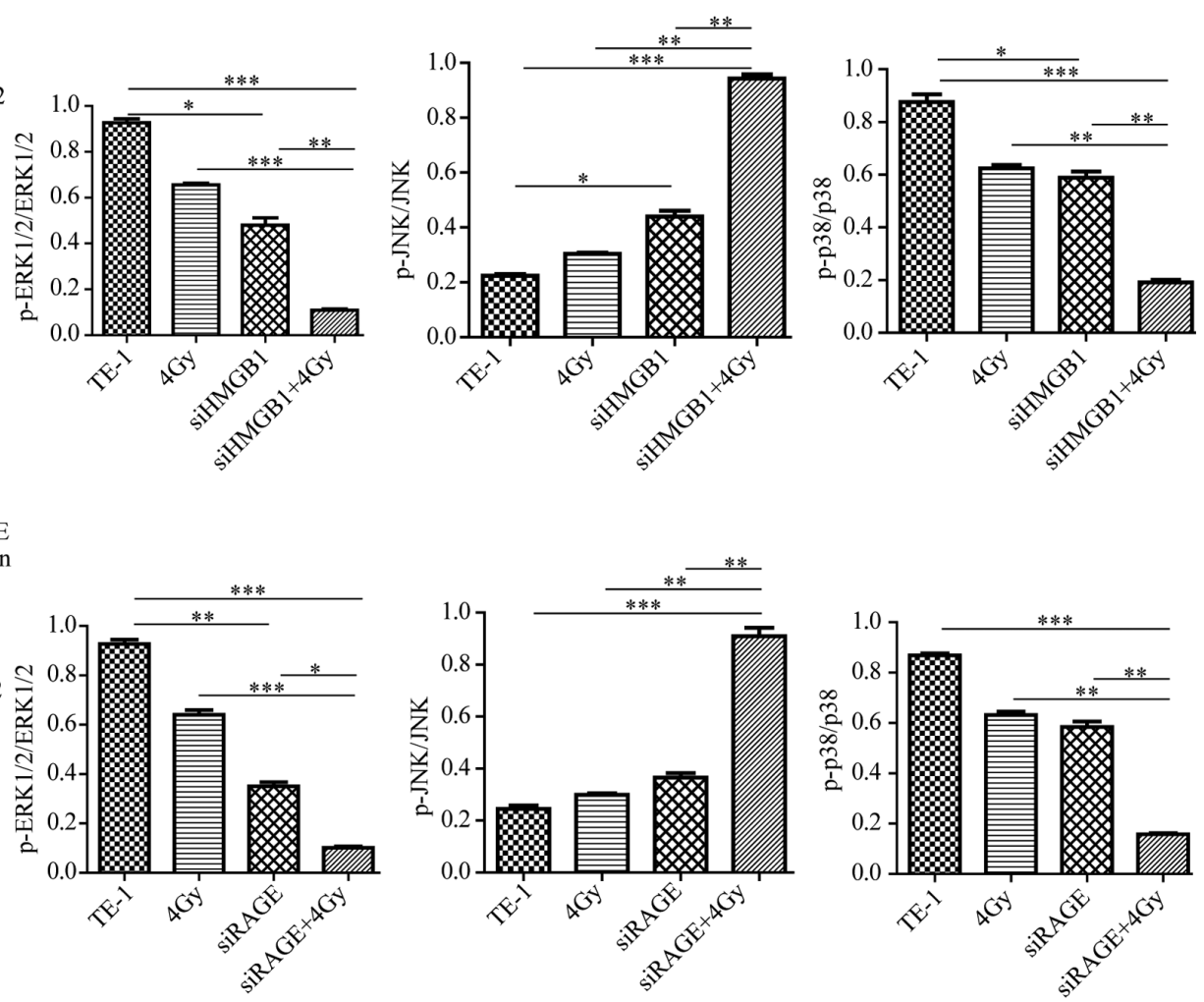

Figure 5. MAPK signaling pathway is involved in the HMGB1-mediated promoting radioresistance. (A) Western blotting was performed to detect the expression of $\beta$-actin, p-ERK1/2, ERK1/2, p-JNK, JNK, p-38 and p-p38 after transfection with or without siHMGB1 for $24 \mathrm{~h}$ prior to radiation for 24 h. (B) Western blotting was performed to validate the transfection efficiency with siRAGE or negative control siRNA for $48 \mathrm{~h}$. (C) Western blotting was performed to detect the expression of $\beta$-actin, p-ERK1/2, ERK1/2, p-JNK, JNK, p-38 and p-p38 after transfection with or without siRAGE for $24 \mathrm{~h}$ prior to radiation for 24 h. The cells were lysed for western blot analysis. Experiments were repeated at least three times with similar results, and only one representative result is shown. ${ }^{*}<0.05$, ${ }^{* *} \mathrm{P}<0.01,{ }^{* * *} \mathrm{P}<0.001$. HMGB1, high mobility group box 1; si, small interfering RNA; RAGE, receptor for advanced glycation end production; p-, phosphorylated.

In contrast to eosinophils from patients with asthma and cutaneous squamous cell carcinoma cells, p38 inhibition reduces $\mathrm{Bcl}-2$ expression and increases apoptosis or augments cutaneous squamous cell carcinoma tumorigenesis via NOX2-driven ROS generation $(44,45)$. The present study revealed that enhancement of apoptosis after radiation combined with HMGB1 knockdown significantly induced downregulation of $\mathrm{p} 38$. This finding suggested that the enhancement of radiation-induced apoptosis by HMGB1 knockdown may be p38-dependent. Whether these differences are due to different cell lines, different disease models or different interventions remains to be investigated in future studies.

The present study focused on the effect of HMGB1 on radiosensitivity and it preliminarily examined the mechanism. The exact mechanism by which HMGB1 promotes radioresistance by using agonists/inhibitors/siRNA of key molecules in the MAPK signaling pathway via RAGE needs further verification as well as evaluation of apoptosis and cell viability in future studies.

In summary, HMGB1 knockdown promoted cell apoptosis and inhibited cell viability. HMGB1 knockdown-enhanced and radiation-induced apoptosis may be involved in the regulation of DNA damage and ROS generation via the MAPK signaling pathway. Therefore, targeting HMGB1 is an attractive strategy to increase the efficacy of radiation therapy for ESCC.

\section{Acknowledgements}

Not applicable.

\section{Funding}

No funding was received.

\section{Availability of data and materials}

The datasets used and/or analyzed during the current study are available from the corresponding author on reasonable request.

\section{Authors' contributions}

GH, SL and LY designed the experiments. GH, SL and RL performed the experiments. GH, XW and CS analyzed the data and prepared the figures. XW, SL, GH and YZ drafted the manuscript and revised it for academic content. YZ made substantial contributions to the design and conception of the present study. GH, RL, CS, XW, YZ, LY and SL confirm the authenticity of the raw data. All authors have read and approved the final manuscript.

\section{Ethics approval and consent to participate}

Not applicable.

\section{Patient consent for publication}

Not applicable. 


\section{Competing interests}

The authors declare that they have no competing interests.

\section{References}

1. Song Y, Li L, Ou Y, Gao Z, Li E, Li X, Zhang W, Wang J, Xu L, Zhou Y, et al: Identification of genomic alterations in oesophageal squamous cell cancer. Nature 509: 91-95, 2014

2. Xu J, Chen Y, Zhang R, Song Y, Cao J, Bi N, Wang J, He J, Bai J Dong L, et al: Global and targeted metabolomics of esophageal squamous cell carcinoma discovers potential diagnostic and therapeutic biomarkers. Mol Cell Proteomics 12: 1306-1318, 2013

3. Rustgi AK and El-Serag HB: Esophageal carcinoma. N Engl J Med 371: 2499-2509, 2014.

4. Lin Y, Totsuka Y, He Y, Kikuchi S, Qiao Y, Ueda J, Wei W, Inoue $\mathrm{M}$ and Tanaka $\mathrm{H}$ : Epidemiology of esophageal cancer in Japan and China. J Epidemiol 23: 233-242, 2013.

5. Zhang Y: Epidemiology of esophageal cancer. World J Gastroenterol 19: 5598-5606, 2013.

6. Wang G, Liu L, Sharma S, Liu H, Yang W, Sun X and Dong Q Bmi-1 confers adaptive radioresistance to KYSE-150R esophageal carcinoma cells. Biochem Biophys Res Commun 425: 309-314, 2012

7. Hosseinimehr SJ: The protective effects of trace elements against side effects induced by ionizing radiation. Radiat Oncol J 33: 66-74, 2015.

8. Luo D, Wang Z, Wu J, Jiang C and Wu J: The role of hypoxia inducible factor- 1 in hepatocellular carcinoma. BioMed Res Int 2014: 409272, 2014

9. Maraldi T: Natural compounds as modulators of NADPH oxidases. Oxid Med Cell Longev 2013: 271602, 2013.

10. Endres L, Begley U, Clark R, Gu C, Dziergowska A Małkiewicz A, Melendez JA, Dedon PC and Begley TJ: Alkbh8 regulates selenocysteine-protein expression to protect against reactive oxygen species damage. PLoS One 10: e0131335, 2015.

11. Rogakou EP, Pilch DR, Orr AH, Ivanova VS and Bonner WM DNA double-stranded breaks induce histone H2AX phosphorylation on serine 139. J Biol Chem 273: 5858-5868, 1998.

12. Probin V, Wang Y and Zhou D: Busulfan-induced senescence is dependent on ROS production upstream of the MAPK pathway. Free Radic Biol Med 42: 1858-1865, 2007.

13. Chung EJ, Urick ME, Kurshan N, Shield W III, Asano H, Smith PD, Scroggins BS, Burkeen J and Citrin DE: MEK1/2 inhibition enhances the radiosensitivity of cancer cells by downregulating survival and growth signals mediated by EGFR ligands. Int J Oncol 42: 2028-2036, 2013.

14. Dhillon AS, Hagan S, Rath O and Kolch W: MAP kinase signalling pathways in cancer. Oncogene 26: 3279-3290, 2007.

15. Ameziane-El-Hassani R, Talbot M, de Souza Dos Santos MC, Al Ghuzlan A, Hartl D, Bidart JM, De Deken X, Miot F, Diallo I, de Vathaire F, et al: NADPH oxidase DUOX1 promotes long-term persistence of oxidative stress after an exposure to irradiation. Proc Natl Acad Sci USA 112: 5051-5056, 2015.

16. Golding SE, Morgan RN, Adams BR, Hawkins AJ, Povirk LF and Valerie K: Pro-survival AKT and ERK signaling from EGFR and mutant EGFRvIII enhances DNA double-strand break repair in human glioma cells. Cancer Biol Ther 8: 730-738, 2009.

17. Lotze MT and Tracey KJ: High-mobility group box 1 protein (HMGB1): Nuclear weapon in the immune arsenal. Nat Rev Immunol 5: 331-342, 2005.

18. Chuangui $\mathrm{C}$, Peng $\mathrm{T}$ and Zhentao Y: The expression of high mobility group box 1 is associated with lymph node metastasis and poor prognosis in esophageal squamous cell carcinoma. Pathol Oncol Res 18: 1021-1027, 2012.

19. Livak KJ and Schmittgen TD: Analysis of relative gene expression data using real-time quantitative PCR and the 2(-Delta Delta $\mathrm{C}(\mathrm{T})$ ) method. Methods 25: 402-408, 2001.

20. Jiao Y, Wang HC and Fan SJ: Growth suppression and radiosensitivity increase by HMGB1 in breast cancer. Acta Pharmacol Sin 28: 1957-1967, 2007.

21. Ellerman JE, Brown CK, de Vera M, Zeh HJ, Billiar T, Rubartelli A and Lotze MT: Masquerader: High mobility group box-1 and cancer. Clin Cancer Res 13: 2836-2848, 2007.

22. Chen CG, Tang P and Yu ZT: Effect of HMGB1 on the VEGF-C expression and proliferation of esophageal squamous cancer cells. Zhonghua Zhong Liu Za Zhi 34: 566-570, 2012 (In Chinese).

23. Yamanaka S, Katayama E, Yoshioka K, Nagaki S, Yoshida M and Teraoka H: Nucleosome linker proteins HMGB1 and histone H1 differentially enhance DNA ligation reactions. Biochem Biophys Res Commun 292: 268-273, 2002.
24. Ke S, Zhou F, Yang H, Wei Y, Gong J, Mei Z, Wu L, Yu H and Zhou Y: Downregulation of high mobility group box 1 modulates telomere homeostasis and increases the radiosensitivity of human breast cancer cells. Int J Oncol 46: 1051-1058, 2015.

25. Zhang H, Gao XS, Zhao J, Xiong W, Zhang M, Li HZ, Zhou DM, Jin $X$ and Zhang DS: Differential gene expression profiles of DNA repair genes in esophageal cancer cells after X-ray irradiation. Chin J Cancer 29: 865-872, 2010.

26. Xie Q, Zhou Y, Lan G, Yang L, Zheng W, Liang Y and Chen T: Sensitization of cancer cells to radiation by selenadiazole derivatives by regulation of ROS-mediated DNA damage and ERK and AKT pathways. Biochem Biophys Res Commun 449: 88-93, 2014.

27. Lam RK, Fung YK, Han W and Yu KN: Rescue effects: Irradiated cells helped by unirradiated bystander cells. Int J Mol Sci 16: 2591-2609, 2015.

28. Guerriero JL, Ditsworth D, Catanzaro JM, Sabino G, Furie MB, Kew RR, Crawford HC and Zong WX: DNA alkylating therapy induces tumor regression through an HMGB1-mediated activation of innate immunity. J Immunol 186: 3517-3526, 2011.

29. Nicholson DW, Ali A, Thornberry NA, Vaillancourt JP, Ding CK, Gallant M, Gareau Y, Griffin PR, Labelle M, Lazebnik YA, et al: Identification and inhibition of the ICE/CED-3 protease necessary for mammalian apoptosis. Nature 376: 37-43, 1995.

30. Lazebnik YA, Kaufmann SH, Desnoyers S, Poirier GG and Earnshaw WC: Cleavage of poly(ADP-ribose) polymerase by a proteinase with properties like ICE. Nature 371: 346-347, 1994.

31. Roehlecke C, Schumann U, Ader M, Brunssen C, Bramke S, Morawietz $\mathrm{H}$ and Funk RH: Stress reaction in outer segments of photoreceptors after blue light irradiation. PLoS One 8: e71570, 2013.

32. Bedard K and Krause KH: The NOX family of ROS-generating NADPH oxidases: Physiology and pathophysiology. Physiol Rev 87: 245-313, 2007.

33. Chen X, Wang Y, Liu J, Xu P, Zhang XM, Tian YY, Xue YM, Gao XY, Liu Y and Wang JH: Synergistic effect of HMGB1 knockdown and cordycepin in the K562 human chronic myeloid leukemia cell line. Mol Med Rep 12: 4462-4468, 2015.

34. Mohammad G, Alam K, Nawaz MI, Siddiquei MM, Mousa A and Abu El-Asrar AM: Mutual enhancement between high-mobility group box-1 and NADPH oxidase-derived reactive oxygen species mediates diabetes-induced upregulation of retinal apoptotic markers. J Physiol Biochem 71: 359-372, 2015.

35. Nair AR, Ebenezer PJ, Saini Y and Francis J: Angiotensin II-induced hypertensive renal inflammation is mediated through HMGB1-TLR4 signaling in rat tubulo-epithelial cells. Exp Cell Res 335: 238-247, 2015.

36. Kehrer JP: Free radicals as mediators of tissue injury and disease. Crit Rev Toxicol 23: 21-48, 1993

37. Ye C, Sun NX, Ma Y, Zhao Q, Zhang Q, Xu C, Wang SB, Sun SH, Wang $\mathrm{F}$ and $\mathrm{Li}$ W: MicroRNA-145 contributes to enhancing radiosensitivity of cervical cancer cells. FEBS Lett 589: 702-709, 2015.

38. Weng H, Deng Y, Xie Y, Liu H and Gong F: Expression and significance of HMGB1, TLR4 and NF- $\mathrm{B}$ p 65 in human epidermal tumors. BMC Cancer 13: 311, 2013.

39. Moser B, Janik S, Schiefer AI, Müllauer L, Bekos C, Scharrer A, MildnerM,Rényi-VámosF, Klepetko W and Ankersmit HJ: Expression of RAGE and HMGB1 in thymic epithelial tumors, thymic hyperplasia and regular thymic morphology. PLoS One 9: e94118, 2014.

40. Kang R, Tang D, Livesey KM, Schapiro NE, Lotze MT and Zeh HJ III: The Receptor for Advanced Glycation End-products (RAGE) protects pancreatic tumor cells against oxidative injury. Antioxid Redox Signal 15: 2175-2184, 2011.

41. Chen YR, Meyer CF and Tan TH: Persistent activation of c-Jun N-terminal kinase 1 (JNK1) in gamma radiation-induced apoptosis. J Biol Chem 271: 631-634, 1996.

42. Shao C, Lyng FM, Folkard M and Prise KM: Calcium fluxes modulate the radiation-induced bystander responses in targeted glioma and fibroblast cells. Radiat Res 166: 479-487, 2006.

43. Faqihi F, Neshastehriz A, Soleymanifard S, Shabani R and Eivazzadeh N: Radiation-induced bystander effect in non-irradiated glioblastoma spheroid cells. J Radiat Res (Tokyo) 56: 777-783, 2015.

44. Maa SH, Wang CH, Liu CY, Lin HC, Huang KH and Kuo HP: Endogenous nitric oxide downregulates the Bcl-2 expression of eosinophils through mitogen-activated protein kinase in bronchial asthma. J Allergy Clin Immunol 112: 761-767, 2003.

45. Liu L, Rezvani HR, Back JH, Hosseini M, Tang X, Zhu Y, Mahfouf W, Raad H, Ragi G, Athar M, et al: Inhibition of p38 MAPK signaling augments skin tumorigenesis via NOX2 driven ROS generation. PLoS One 9: e97245, 2014.

This work is licensed under a Creative Commons Attribution-NonCommercial-NoDerivatives 4.0 International (CC BY-NC-ND 4.0) License. 